\title{
Política Cultural e Unidades Culturais de Infocomunicação
}

\section{Cultural Policy and Cultural Units of Infocommunication}

Marco Antônio de Almeida ${ }^{* *}$

Recebido em: 17.03.2017.
Aprovado em: 25.08.2017
** Livre-docente em Ciências da
Informação pela USP, professor e
pesquisador da FFCLRP-USP e
também do Programa de Pós-
Graduação em Ciência da Informação
da ECA/ USP. Email:
marcoaa@ffclrp.usp.br

Resumo: o tema do trabalho é a mediação cultural em espaços institucionais e os impactos proporcionados pelas Tecnologias de Informação e Comunicação (TICS) nesse processo. O texto analisa as políticas culturais em unidades de informação entendidas como espaços culturais. Parte inicialmente da discussão dos próprios termos "Unidades de Informação" e de "Centros Culturais", considerando a hipótese de que a incorporação de concepções mais alargadas do conceito de cultura e a presença cada vez maior das TICs ampliam a convergência entre esses espaços. $O$ foco concentra-se nas potencialidades de formação e de empoderamento cultural proporcionadas pelas políticas desenvolvidas por estas instituições. Nessa perspectiva, analisa os exemplos dos Pontos de Cultura, no Brasil, e o Sistema de Bibliotecas Públicas de Medellín, na Colômbia. Conclui que essas experiências permitem visualizar possibilidades de constituição de novas ações e cadeias de mediações da cultura, numa perspectiva muito mais dialógica que impositiva.

Palavras-Chave: Políticas Culturais; Mediações; Tecnologias de Comunicação e Informação; Democracia Cultural.
Abstract: the theme of the work is cultural mediation in institutional spaces and the impacts provided by Information and Communication Technologies (ICTs) in this process. The text analyzes cultural policies in units of information understood as cultural spaces. It starts from the discussion of the terms "Information Units" and "Cultural Centers", considering the hypothesis that the incorporation of broader conceptions of the concept of culture and the increasing presence of ICTs increase the convergence between these spaces. The focus is on the potential for training and cultural empowerment provided by the policies developed by these institutions. From this perspective, he analyzes the examples of Culture Points in Brazil and the Public Library System in Medellín, Colombia. It concludes that these experiences allow us to visualize possibilities of constitution of new actions and chains of mediations of the culture, in a perspective much more dialogic than impositive.

Keywords: Cultural Policies; Mediations; Communication and Information Technologies; Cultural Democracy. 


\section{Introdução}

Podemos dizer que as relações entre cultura, política e tecnologia existiram desde sempre em todas as sociedades humanas, o que é bastante óbvio. Por outro lado, certas inflexões históricas foram determinantes em estabelecer novas perspectivas para estas relações, como no caso da Modernidade. A chamada Modernidade considerando-se aqui seu caráter eminentemente ocidental - foi um período de radicais mudanças que ocorreram simultaneamente e se influenciaram entre si: mudanças no campo da política, com a implantação dos Estados-Nação; mudanças no campo sociocultural, com os ideais do Iluminismo e novas concepções do indivíduo e da sociedade relacionadas; mudanças no aparato técnico das sociedades, com as consequências decorrentes da Revolução Industrial. Desse modo, desde o século XVIII, algumas questões permanecem: Como as tecnologias que surgem neste contexto permitem articular a eclosão do indivíduo e a inclusão na coletividade? Como eles provocam uma inflexão decisiva no que se entende por "cultura"?

No contexto social das interações comunicacionais, até o século XV, predominaram as interações face a face. Com o Renascimento e, posteriormente, com o Iluminismo, inicia-se um processo de instituição de novas redes de transmissão, e também de novas formas de interação e novos tipos de relacionamento social. Com o surgimento de novos meios de comunicação, a interação se dissocia do ambiente físico. Surgem então as interações mediadas aquelas que implicam o uso de um meio técnico, como papel, fios elétricos, ondas eletrônicas, etc. --, e as interações quase-mediadas - as relações sociais estabelecidas pelos meios de comunicação de massa como livros, jornais, rádio, televisão, e que implicam numa ampla disponibilidade de informação e conteúdo simbólico no espaço e no tempo (THOMPSON, 1998).

As conseqüências históricas para o intercâmbio de informação e conteúdo simbólico provocadas pelas mudanças tecnológicas (imprensa e, posteriormente, meios eletrônicos) fazem com que as interações face a face cedam cada vez mais espaço para as interações mediadas e quase-mediadas. Podemos perceber aqui ecos de "O Narrador", de Walter Benjamin (1987b), e sua reflexão sobre as novas formas de se vivenciar as experiências e integrar os conhecimentos. Para Thompson, os indivíduos, de um modo geral, passam cada vez mais a utilizar ou a se mobilizar em busca de informações e conteúdo simbólico de fontes (e pessoas) distantes de seu cotidiano: "a criação e a renovação das tradições são processos que se tornam sempre mais interligados ao intercâmbio simbólico mediado.” (THOMPSON, 1998, p. 82).

Desse modo, a organização social passa a se relacionar também com os conteúdos da interação quase-mediada. Relembrando Berger e Luckmann (1974), existe uma forte relação entre as instituições e os papéis sociais, que acionam a adequação do comportamento às estruturas previamente definidas. Assim, para Thompson, há uma dialética entre processos de reflexividade e de monitoramento, e os meios de comunicação produzem um impacto na natureza e nas relações entre esses processos. Para ele, em 
qualquer forma de interação os indivíduos estão sempre utilizandose de um repertório de recursos e habilidades que adquiriram de diversas maneiras. Eles atuam sempre em contextos específicos que simultaneamente criam e limitam as possibilidades disponíveis. Entretanto, nos casos das interações mediadas e das interações quase-mediadas, "os campos de interação adquirem uma complexidade adicional, uma vez que eles estão agora dilatados no espaço (e talvez também no tempo) e os participantes podem estar situados em contextos os mais diversos em termos de características institucionais e estruturais" (THOMPSON, 1998, p. 84)

As modalidades de interação relacionam-se com os diversos contextos sociais. Se, aparentemente, a proliferação dos fluxos comunicacionais e informacionais numa escala jamais vista até então possibilitou que a cultura aparentemente "esteja em toda parte", vale a pergunta: Onde ela começa e onde ela termina? $\mathrm{Na}$ realidade, a cultura se articula, em todas as instituições sociais, com as dimensões políticas e econômicas. Uma das consequências da mudança de paradigmas nas ciências humanas e sociais foi a expansão do termo "cultura" a um espectro mais amplo e abrangente de instituições e práticas, sugerindo que cada uma delas requer seu próprio universo distinto de significados, gerando assim sua própria "cultura" (da cultura da empresa à cultura do gueto, da cultura dos torcedores de futebol à cultura dos militares, da cultura dos evangélicos à cultura dos transexuais, etc.). Em outras palavras, essas dimensões se constituem mutuamente, o que significa dizer que toda prática social possui condições culturais de existência, na medida em que dependem de "valores" e "significados" para funcionar e produzir efeitos. Esse é o gancho de Hall para tematizar a questão da regulação das culturas: "No cerne desta questão está a relação entre cultura e poder. Quanto mais importante - mais 'central' - se torna a cultura, tanto mais significativas são as forças que a governam, moldam e regulam" (HALL, 1997, p. 29).

Desse modo, a cultura passou a ser encarada como um recurso para os sujeitos.(YÚDICE, 2006). A cultura considerada como recurso, nesse caso, não se limitaria ao simples papel de mercadoria: administrar esses recursos visando atingir distintos objetivos tornou-se um desafio para Estados, empresas e movimentos sociais. A configuração contemporânea do sistema cultural, em toda sua complexidade, implica crescentemente no desenvolvimento de aparatos de informação cada vez mais sofisticados, envolvendo recursos físicos e humanos. Tornam-se centrais as preocupações com o gerenciamento, a conservação, o acesso, a distribuição e o investimento em cultura. A cultura passa a assumir o papel de poder público, com funções pedagógicas e disciplinares. Yúdice enxerga na arte e na cultura um potencial para estimular o crescimento econômico e melhorar as condições sociais de determinadas comunidades. A arte e a cultura acabam por cobrir espaços não preenchidos pelo Estado, que, pressionado pelas políticas de inspiração neoliberal, transfere progressivamente para a sociedade civil a responsabilidade pela assistência social da população. Nesse contexto, a promoção da cultura como recurso requer a adoção de uma estratégia orientada pelos processos de 
gestão, entrando em choque, portanto, com a premissa gramsciana que define a cultura como um terreno de luta. Ambas as perspectivas disputam espaço no cenário atual e podem ser percebidas na dialética concreta das muitas experiências em andamento. Como observa Paul Tolila (2007), é a economia cultural valendo-se da cultura como recurso para outros fins.

A compreensão da cultura como campo crucial de investimento faz com que ela seja tratada como qualquer outro recurso, sendo que em países tão diversificados culturalmente como os da América Latina, em particular o Brasil, os investimentos em cultura sejam realizados apenas em relação a algumas manifestações culturais específicas, as quais apresentam mais possibilidade de retorno - mesmo que de forma indireta - como incentivos fiscais, valor publicitário ou a comercialização da atividade cultural, não importando muito se os valores culturais dos residentes serão compreendidos e honrados quando esses recursos forem destinados.

A ideia de que as necessidades decorrentes das diferenças culturais de um povo deveriam ser reconhecidas transformou-se num poderoso argumento que encontrou receptividade em vários fóruns internacionais. À medida que a identidade social é desenvolvida num contexto cultural coletivo, discute-se a necessidade de se reconhecer as diferenças e os contextos pelos quais são estabelecidas as noções de responsabilidade e direitos desenvolvidos na comunidade. Assim, a cultura "se aproxima da comunidade, expressa a busca da justiça social e os direitos do cidadão, além de ser sobredeterminada pela penetração da lógica do capital nos recessos ainda recônditos da vida" (YÚDICE, 2006, p. 44).

As questões relacionadas à mediação da informação e da tecnologia, no sentido de sua apropriação social, tornam-se estratégicas nesse processo (ALMEIDA, 2014). Por outro lado, é importante não esquecer que vivemos em sociedades extremamente desiguais e que, hoje, a divisória digital apontada por Castells (2003) seja talvez um dos elementos de divisão social mais importante - as capacidades culturais e educativas para a utilização da internet. Do ponto de vista das políticas culturais, o desafio consiste em estabelecer mediações educativas e formadoras contínuas, capazes de possibilitar aos sujeitos a apropriação desses saberes. As TICs mudam de modo rápido e profundo a forma como nos comunicamos com outras pessoas e nos relacionamos com os diversos fluxos informacionais locais e globais. A apropriação social dessas tecnologias é continuamente reinventada, conforme possibilidades são exploradas e outras caem em desuso. Assim seus limites comunicacionais são modificados e expandidos de forma constante.

\section{Políticas e Ações Culturais: das concepções às práticas}

As reflexões anteriormente desenvolvidas permitem-nos estabelecer alguns parâmetros para esboçarmos uma definição de políticas culturais. 
Antes de mais nada, interessa-nos uma definição suficientemente abrangente do termo. Como observa Isar (2013), muitas pesquisas acerca das políticas culturais acabam por restringir-se exclusivamente às políticas levadas a cabo pelos Estados (em seus diversos níveis administrativos). Na medida em que essas políticas de Estado estão longe de serem as únicas determinantes do que Isar denomina de "sistema cultural", uma abordagem desse tipo acaba por ser limitante. Para o autor, a vida cultural está sendo moldada para além dos canais formalmente definidos ou delimitados pelo Estado. O desafio de pensar uma definição mais abrangente de "políticas culturais" é fazer justiça a duas dimensões complementares que a envolveriam. A primeira dessas dimensões relaciona-se com o crescente peso epistemológico e simbólico da cultura hoje, na medida em que ela (com)forma e (trans)forma o entendimento das pessoas e grupos, suas identidades e suas visões de mundo. A segunda dimensão, por sua vez, relaciona-se à substantividade da centralidade da cultura: sua real estruturação e organização, a distribuição dos recursos materiais e econômicos envolvidos e o papel desempenhado pelos diversos atores empíricos nessa dinâmica (Estado, instituições, organizações, empresas, grupos, etc.).

Outro aspecto importante para essa questão reside no ideal democrático atribuído a esse tipo de política, mas que nem sempre é explicitado. Nesse caso, como observa Isar, é importante fazer uma distinção entre "democratização da cultura e democracia cultural: dar às pessoas acesso a um conjunto predeterminado de bens e serviços culturais ou dar a elas instrumentos de agenciamento, vocalização e representação em termos de suas próprias expressões culturais" (ISAR, 2013, p. 29). A primeira idéia, de democratização da cultura, implica num conjunto de bens culturais previamente legitimado, ao qual seria dado acesso às massas. Já a segunda idéia, de democracia cultural, buscaria ampliar e diversificar o acesso não só aos bens, mas também aos meios de produção e distribuição cultural, dando às pessoas o agenciamento para se envolverem nos debates sobre o valor das próprias identidades e expressões culturais.

O atual cenário estimula a repensar as políticas culturais, considerando-se desde sua formulação mais geral até seus contextos locais, abrangendo toda a cadeia de mediações que vão do macronível do Estado ao micronível dos usuários-cidadãos. Obviamente é prematuro afirmar que vivemos um estado de "democracia cultural", nos termos de Isar, de novas práticas dos sujeitos, mas é claro que o processo tecnológico em curso descortina novas e promissoras possibilidades nesse sentido. $\mathrm{O}$ pensador alemão Niklas Luhmann (1985), em sua concepção de sistemas sociais, assinalou o papel preponderante desempenhado pela comunicação e suas tecnologias. Os meios de comunicação e informação, no caso da cultura, além de permitirem a intercompreensão mútua entre os atores sociais, também são um elemento motivador dos mesmos, na medida em que sugerem visões de mundo, possibilidades de ação e potenciais resultados. Os meios de comunicação, enquanto expressão do poder e poder em si, 
buscam delimitar o espaço de seleção dos atores sociais - sejam classes sociais, grupos de interesse, coletividades, instituições ou indivíduos. Assim, nas sociedades contemporâneas complexas, “os códigos comunicativos podem tornar-se diferentes e concorrentes, condicionando relações de poder e de verdades, de aceitação ou recusa de valores, de consenso ou conflito de objetivos" (CUNHA, 2011, p. 40).

Entretanto, a delegação de poder e de recursos por parte do Estado às empresas e às entidades da sociedade civil acabou por nublar essa distinção. As políticas culturais envolvem, portanto, desde instituições (governo, ONGs, associações) a aparatos infraestruturais e agentes humanos (gestores, técnicos, usuários), em diversos níveis (ALMEIDA, 2014). Um aspecto suplementar que torna essa discussão ainda mais complexa é o deslocamento do termo "cultura" para o campo da economia e sua reapropriação no âmbito da formulação de políticas públicas de cultura em todos os níveis (do nacional ao local). A compreensão e a prática da cultura na contemporaneidade são bastante complexas, uma vez que diversos fatores exercem transformações "naquilo que entendemos por cultura e o que fazemos em seu nome" (YÚDICE, 2006, p. 27).

Desse modo, considerarei as políticas culturais como uma sinergia de ideias, valores, normas, instrumentos de ação, operações, atores sociais, dispositivos institucionais, orçamentos, instituições etc. Uma política organiza uma reunião de medidas concretas, compreendendo decisões de natureza diversa, inscrevendo-se num quadro de conjunto construído pelas representações dos problemas que constituem uma agenda pública. O quadro geral das políticas culturais mistura questões normativas e questões de fato, ou seja, o que se deseja fazer e o que de fato se faz, não se constituindo de ações isoladas ou fragmentadas. Podemos entender as políticas culturais como um conjunto coordenado de mediações visando um determinado fim (embora as mediações possam ocorrer sem necessariamente estar subsumidas no âmbito de uma política cultural institucionalizada).

Por sua vez, o conceito de mediação também apresenta uma polissemia bastante complexa. De um ponto de vista geral, ocupa papel central nas explicações das Ciências Sociais em relação aos processos gerais de sociabilidade e construção do conhecimento. Do ponto de vista especializado, recobre semanticamente um rol de atividades bastante díspares entre si, circulando das tradicionais concepções de "atendimento ao usuário" às atividades dos mediadores culturais nas instituições (museu, biblioteca, arquivo, centro cultural, etc.) ou à construção de produtos e de políticas de capacitação e formação. Desse modo, por ora trataremos de assumir a plasticidade do conceito, sem buscar encapsulá-lo numa definição consensual, mas problematizando-o contextualmente (ALMEIDA, 2008, DAVALLON, 2007). As TICs possibilitam novas perspectivas nesse campo, mas, ao mesmo tempo, acrescentam mais camadas de complexidade ao processo. No caso das mediações tecnológicas, proporcionadas por ferramentas informacionais (portais, sites, weblogs), procuraremos entendê-las dentro das dinâmicas próprias das redes sociotécnicas. As redes sociotécnicas 
instalam uma forma comunicativa constituída de fluxos e trocas de informações "de todos para todos" - são redes sociais nas quais as plataformas disponibilizadas pelas TICs desempenham papel importante, mas cuja interação não se resume, necessariamente, a esse suporte. O que interessa-nos destacar é que subjaz, na opção pelo uso do termo redes sociotécnicas, uma concepção de internet como artefato cultural, no qual ocorre uma interação entre as relações on lineloff line que são determinantes para os usos e configurações dessa tecnologia. No Brasil contemporâneo, é possível fazer uma leitura nessa perspectiva das disputas que se desenrolam no campo das políticas públicas culturais. $\mathrm{Na}$ perspectiva da "democracia cultural" de Isar, as mediações culturais desempenham papel estratégico no âmbito das políticas culturais no sentido de apontarem para a possibilidade de "empoderamento" (enpowerment) dos indivíduos e grupos.

Assim, a partir de quatro definições de cultura e suas respectivas características, nos propusemos estabelecer uma tipologia "ideal", no sentido weberiano (WEBER, 1992), que dê conta de balizar as iniciativas concretas de políticas públicas em seus contextos específicos. Podemos pensar, portanto, nessas ações que visam regular a cultura buscando produzir determinados efeitos nos indivíduos e nos grupos como "políticas culturais" (exercendose no âmbito do Estado, em parceria com o mesmo ou totalmente fora de seu âmbito, exclusivamente na dimensão civil da sociedade). O quadro a seguir sintetiza essas oposições:

\begin{tabular}{|l|l|l|}
\hline Sentido & Âmbito de ação emancipatório & $\begin{array}{l}\text { Âmbito de ação mercadológico } \\
\text { (capitalista) }\end{array}$ \\
\hline $\begin{array}{l}\text { Antropológico: modos e } \\
\text { estilos de vida }\end{array}$ & $\begin{array}{l}\text { "resgate" e/ou valorização das } \\
\text { culturas tradicionais }\end{array}$ & $\begin{array}{l}\text { "folclorização" das mercadorias, } \\
\text { turismo étnico, etc. }\end{array}$ \\
\hline $\begin{array}{l}\text { Sociológico: comportamento } \\
\text { declarativo/diferenciação } \\
\text { social }\end{array}$ & $\begin{array}{l}\text { políticas de acesso e apropriação } \\
\text { dos bens culturais }\end{array}$ & $\begin{array}{l}\text { gerenciamento/planejamento da } \\
\text { produção de mercadorias } \\
\text { culturais }\end{array}$ \\
\hline $\begin{array}{l}\text { Patrimonial: corpus de obras } \\
\text { reconhecidas e valorizadas }\end{array}$ & $\begin{array}{l}\text { processos de educação formal e/ou } \\
\text { informal, atividades de mediação } \\
\text { cultural }\end{array}$ & $\begin{array}{l}\text { Ações semelhantes, pensadas, } \\
\text { porém, dentro da lógica de } \\
\text { mercado (lucro) }\end{array}$ \\
\hline $\begin{array}{l}\text { Cultura como recurso sócio- } \\
\text { econômico }\end{array}$ & $\begin{array}{l}\text { promoção da cidadania cultural, } \\
\text { geração de renda, } \\
\text { desenvolvimento social }\end{array}$ & $\begin{array}{l}\text { Legitimação/afirmação dos } \\
\text { valores e grupos hegemônicos, } \\
\text { seus interesses e lobbies. }\end{array}$ \\
\hline
\end{tabular}

Quadro 1: Sentidos do termo cultura e âmbitos das políticas culturais Adaptado de ALMEIDA, 2014. 
Essas oposições não existiriam em "estado puro", na realidade empírica concreta das experiências, servindo mais como parâmetros modelares para indicar a dinâmica complexa dos contextos locais. Elas oscilariam pela presença maior de um polo representado por ações emancipatórias (no sentido habermasiano do termo, relacionado ao desenvolvimento da autonomia dos sujeitos) a outro polo, de ações atreladas aos interesses hegemônicos, principalmente via lógica de mercado, reforçando o status quo. $\mathrm{Na}$ perspectiva proposta por Isar, o primeiro polo tenderia à democracia cultural, enquanto o segundo já se deslocaria para uma ideia de democratização da cultura, de acesso ao conjunto de bens "legitimados" - sendo o mercado uma dessas instâncias de legitimação.

Uma questão que mereceu especial reflexão é a de como as políticas culturais, associadas às tecnologias de informação e comunicação (TICs), têm possibilitado a emergência de novos ambientes de informação/comunicação conectados a redes sociais, e redimensionado a relação dos indivíduos com a produção, a prática e a própria construção de identidades e memórias culturais. Estes ambientes surgem a partir de iniciativas do Estado ou, quando são decorrentes de iniciativas da sociedade civil, recebem o apoio do mesmo. A constituição de redes sociais a partir das unidades de informação que alocam essas políticas culturais de acesso e apropriação da informação e do conhecimento tem sido uma das conseqüências desse processo, nem sempre prevista, entretanto, no escopo inicial dessas políticas.

Nosso objetivo foi o de nortear algumas reflexões acerca das conexões entre políticas culturais, acesso às TICs e processos de produção, circulação e apropriação da informação cultural tendo em conta as experiências concretas de políticas e ações culturais (a serem discutidas principalmente na segunda parte). Uma das preocupações centrais é a de compreender como se estruturam as configurações das redes sociotécnicas e seu uso como mecanismo de coordenação sociocultural. O que se busca, nesse caso, é identificar a constituição, o uso e a apropriação das redes sociais e seus efeitos sobre as formas de organização das políticas e ações culturais. Assim, por exemplo, no âmbito das iniciativas recentes do Ministério da Cultura (MinC) e de outros órgãos de fomento da cultura, esse processo é perceptível na elaboração de programas, na abertura de linhas de crédito e na formação e qualificação de pessoal técnico apto a lidar com esse aspecto de "gestão" das políticas culturais nos diferentes níveis de incidência das mesmas. O outro ponto relativo às questões que envolvem as políticas culturais e os processos de mediação é a presença, bastante marcante em alguns casos, de processos de acesso/divulgação-circulação da informação e de processos de acesso/apropriação-formação de competências técnico-culturais. Em outras palavras: a preocupação, de um lado, de fazer circular a informação e torná-la pública, especialmente a informação cultural; e, de outro, a preocupação em 
${ }^{1}$ Para uma perspectiva teórica da discussão, vide PIGNATARI, 2002 e LOGAN, 2012. Uma discussão mais histórica da evolução do conceito e de suas aplicações encontra-se em GLEICK, 2013.

\section{Marco Antônio de Almeida}

capacitar e formar os atores envolvidos (individuais e coletivos), traduzida numa oferta de cursos, oficinas, seminários, projetos abertos, etc. Aqui se pode perceber melhor a sintonia com algumas das ideias de Habermas (1998). Devemos lembrar que, para ele, a "competência comunicativa" não é expressão de alguma entidade abstrata, nem atributo da sociedade como um todo, mas um processo que, a qualquer instante, pode ser desencadeado pela disposição e capacidade dos parceiros da interação de sustentar discursivamente suas posições mediante argumentos. Os atores são, portanto, portadores de processos de aprendizado, produtos de um processo de formação de sujeitos (ALMEIDA, 2012).

\section{Centros de Informação e Cultura, entre o espaço e o ciberespaço}

A utilização do termo "Unidades de Informação" remete, de um modo geral, à infra-estrutura física do ambiente de trabalho e de atuação do profissional da informação. Santos e Ribeiro (2003, p. 243) referem-se a "arquivos, discotecas, filmotecas, hemerotecas, mapotecas, pinacotecas, os diversos tipos de centros de informação, os museus e as bibliotecas que se dedicam às atividades de informação". Optam, assim, mais pela enumeração do que pela definição. De todo modo, os autores referem-se aos locais onde são oferecidos "serviços de informação" - que, numa definição circular, seriam os conjuntos de serviços oferecidos pela unidades de informação, que permitiriam a transmissão/transferência da informação para os usuários. Retornando a Santos e Ribeiro, ao final do verbete citado anteriormente há uma remissão para o termo "biblioteca". Entre as definições elencadas para definir esta unidade de informação, está: “um centro de transferência de informação, composta pelos mais diversos tipos de documentos (livros, periódicos, slides, fotografias, filmes, mapas, discos, fitas magnéticas, vídeos, partituras, etc.). Um espaço dinâmico o qual atende a pesquisa, estudo e lazer" (SANTOS, RIBEIRO, 2003, p. 30).

Sem entrar no mérito da discussão, bem polêmica por si só, da definição do que é "informação", o que se deduz das observações acima é que a pré-condição de existência de uma unidade de informação é a disponibilidade de um local físico que a abrigue, no qual o acervo possa ser devidamente armazenado e organizado. Por outro lado, a criação de um serviço de informação não depende necessariamente da existência de uma unidade de informação, podendo ser desenvolvido de acordo com as necessidades da instituição ou organização que decida criá-lo e/ou adotá-lo. O desenvolvimento das TICs, particularmente das redes telemáticas, possibilitou, entre outras, o surgimento, o desenvolvimento e a multiplicação de bibliotecas digitais e virtuais, colocando em xeque a diferenciação entre unidades de informação e serviços de informação strictu sensu. $\mathrm{O}$ universo de bits e bytes não seria, por si só, uma unidade de informação? Na medida em que se converte em digital ou virtual, a biblioteca se reduz a um mero 
2 Locus na genética é o local fixo num cromossomo onde está localizado determinado gene ou marcador genético. Já na matemática e em geometria, locus é um lugar geométrico que consiste no conjunto de pontos do espaço que gozam de uma determinada propriedade matemática. Em ambos os casos, curiosamente, locus é um marcador de um tipo de informação.

3 A pesquisa original envolveu estudos e observações de instituições no Brasil, Espanha e Colômbia. Para este artigo, entretanto, nos limitaremos a discutir as experiências dos Pontos de Cultura e das bibliotecas de Medellín. Para maiores detalhes, vide ALMEIDA, 2014.

${ }^{1}$ Software livre (Open Source) é um movimento que se baseia no compartilhamento do conhecimento tecnológico. Refere-se a programas de computador cujo código-fonte é aberto e livre, isto é, pode ser usado, copiado, melhorado e redistribuído sob as condições estipuladas em sua licença. Isso não ocorre nos programas comerciais, cujos direitos pertencem, em sua maioria, às grandes corporações de desenvolvimento de software. Alguns autores e ativistas diferenciam o movimento do software de código aberto daquele do software livre. Consideram que, embora ambos tenham como premissa a produção colaborativa, o movimento do software livre agrega uma dimensão política que não seria prioritária na filosofia do código aberto, este serviço ou pode ser considerada também uma unidade, um centro onde se busca e se troca informação?

A ideia, sempre reiterada, de que vivemos numa "sociedade da informação" joga com o fato de que, além dos meios de comunicação tradicionais - jornais, rádio, televisão, telefone também lidamos hoje com outros meios, mais recentes e interativos, como computadores e laptops com acesso à Internet, câmeras, celulares, Ipods, GPS, etc. Uma questão formulada com cada vez mais frequência é se a organização da informação nesses ambientes é a mesma de uma unidade de informação tradicional. Clay Shirky (2010) lembra-nos que na web "não existem estantes", e que as classificações podem ser feitas de modos alternativos aos tradicionais, inclusive pelos próprios usuários - entraríamos aqui no território das folksonomias (WALL, 2007).

Um novo locus para os profissionais e usuários da informação? Antes de pensar nisso, vale refletir um pouco sobre o conceito. Locus significa lugar, em latim, e pode ser usado em diversos sentidos e para várias áreas, como na Psicologia, na Genética, na Matemática, etc. ${ }^{2}$ Numa perspectiva mais ligada às Ciências Sociais e à História, pode ajudar a compreender melhor uma distinção entre "espaço" e "lugar". De acordo com as definições e origens dessas palavras, de um modo geral estabeleceuse a relação entre os dois conceitos como sendo a de que o lugar é o espaço ocupado, basicamente habitado por seres humanos (já que uma de suas definições sugere sentido de povoado, região ou país).

O acréscimo da ideia de habitar, neste contexto, incorpora um novo elemento à concepção de lugar - o homem. O espaço físico assume daí um significado e valor antropológico que o alça à condição de lugar em razão da mera presença do homem, seja para acomodá-lo fisicamente, como o seu lar, seja para servir como palco para as suas atividades. Em larga medida, se diz que quando o espaço nos é inteiramente familiar, torna-se um lugar. No fundo, é essa oposição que preside a distinção proposta por Marc Augé: "Se um lugar pode se definir como identitário, relacional e histórico, um espaço que não pode se definir nem como identitário, nem como relacional, nem como histórico definirá um não-lugar” (AUGÉ, 1994, p. 73). Augé defende a hipótese de que a supermodernidade é produtora de não-lugares, locais que induzem a um rápido movimento associado a uma não personalização do espaço e do indivíduo. Ao referir-se ao não-lugar, Augé concebe este como uma espécie de qualidade negativa do lugar, de uma ausência do lugar em si mesmo: “o espaço do não-lugar não cria nem identidade singular nem relação, mas sim solidão e similitude" (AUGÉ, 1994, p. 95).

Nesse sentido, estamos entendendo aqui locus como este lugar culturalmente significativo, perpassado pelas atividades humanas que lhe dão valor e sentido. Assim, buscaremos elencar a seguir alguns locus de informação e cultura que abrem possibilidades interessantes, quiçá inéditas, e que ainda permanecem pouco explorados ${ }^{3}$. São espaços tradicionais, mas com novas configurações, como as bibliotecas de Medellín. Também trataremos, por outro lado, de espaços que tradicionalmente não mereceram a mesma atenção que bibliotecas, arquivos e museus, 
último enfatizando apenas a forma de produção do software.

${ }^{4}$ Software livre (Open Source) é um movimento que se baseia no compartilhamento do conhecimento tecnológico. Refere-se a programas de computador cujo código-fonte é aberto e livre, isto é, pode ser usado, copiado, melhorado e redistribuído sob as condições estipuladas em sua licença. Isso não ocorre nos programas comerciais, cujos direitos pertencem, em sua maioria, às grandes corporações de desenvolvimento de software. Alguns autores e ativistas diferenciam o movimento do software de código aberto daquele do software livre. Consideram que, embora ambos tenham como premissa a produção colaborativa, o movimento do software livre agrega uma dimensão política que não seria prioritária na filosofia do código aberto, este último enfatizando apenas a forma de produção do software.

\section{Marco Antônio de Almeida}

seja pelo seu aparecimento mais recente, ou por não serem considerados até então como potenciais campos de atuação para os profissionais da área ou para a prestação de serviços para os "usuários". Não será o caso de menosprezar os espaços ditos "tradicionais" - muito pelo contrário, já que várias das habilidades e conhecimentos requeridos por estes também o são nos novos espaços.

As informações sobre estes ambientes foram parcialmente obtidas por meio de fontes como publicações e sites, mas em sua maior parte são provenientes de visitas, observações in loco, entrevistas com administradores e conversas com seus usuários (aos quais agradeço imensamente). Do ponto de vista metodológico, não se tratam de estudos comparativos, visto que a própria seleção dos casos não foi construída antecipadamente, seguindo critérios préestabelecidos com o objetivo de construir um instrumental unificado de análise. As experiências brasileiras já vinham sendo alvo de minha atenção, e as experiências estrangeiras somaram-se às reflexões em virtude de oportunidades decorrentes de outros projetos. Nesse sentido, não houve um protocolo comum aplicado às observações e às entrevistas. Também seria muita pretensão de minha parte, por outro lado, chamar a este processo de estudo etnográfico, já que não possuiu o grau de planejamento e imersão que caracterizam este tipo de trabalho, e os períodos dedicados à análise e observação de cada experiência variaram muito.

Entretanto, essa vivência mista de pesquisador e usuário ocasional foi fundamental para a elaboração de algumas das observações e concepções que se seguem. Seguindo os mofados manuais de técnicas de pesquisa, essa atividade poderia ser classificada como pesquisa exploratória; prefiro, entretanto, pensála como uma flânerie intelectual e sensorial, à la Walter Benjamin. Trata-se antes de uma cartografia exploratória, e de um convite à reflexão e, porque não, à ação política. $\mathrm{O}$ que se pode perceber foi um grande potencial para as mediações culturais da informação, especialmente no território dinâmico onde se cruzam a cultura, as redes telemáticas e as TICs, bem como as comunidades locais de artistas, produtores e usuários.

\section{O Programa Cultura Viva e os Pontos de Cultura}

No primeiro ano do governo Lula, mais precisamente em agosto de 2003, realizou-se em Brasília o seminário "O software livre e o desenvolvimento do Brasil”. No folder do evento, a opção pelo software livre ${ }^{4}$ era justificada devido a seu uso coletivo estimular a produção e troca de conhecimento em todos os níveis da sociedade, orientando-se para as necessidades específicas das comunidades e favorecendo a inclusão digital. Como observa Hermano Vianna, não se tratava de um panfleto de extremistas hackers fora do poder, mas parte de um discurso oficial de governo, "uma profissão de fé numa verdade aparentemente inquestionável: o software livre estava sendo apresentado como a vanguarda, e o Brasil seria também um país de vanguarda por legitimá-lo como 
${ }^{5}$ A referência a um "espírito hacker" parte do entendimento dos hackers como indivíduos que elaboram e modificam software e hardware de computadores, seja desenvolvendo funcionalidades novas, seja adaptando as antigas. E importante diferencí́los dos crackers, termo usado para designar quem pratica a quebra (ou cracking) de um sistema de segurança, de forma ilegal ou sem ética. Este termo foi criado em 1985 por hackers em defesa contra o uso jornalístico equivocado do termo hacker.

6 Gilberto Gil lançou, em 1997 menos de dois anos depois do início do uso comercial da internet no Brasil, o álbum Quanta, com a música "Pela internet", a primeira música brasileira a ser lançada via internet, ao vivo A sincronia do artista com os novos paradigmas do mundo digital teria um novo momento de visibilidade em junho de 2004, quando Gil, já ministro, se tornou um dos primeiros un primeiro compositores, no mundo, a libera uma música - "Oslodum" - para acesso e compartilhamento livres na internet, por meio de uma forma de licenciamento alternativa ao copyright, o copyleft. foco das preocupações do Estado" (VIANNA, 2011, p. 316). A construção de políticas culturais digitais durante a gestão do ministro Gilberto Gil (2003-2008) à frente do MinC, e mantidas posteriormente por seu sucessor Juca Ferreira (2008-2010), estavam em perfeita consonância com o "espírito hacker" que impregnou a opção pelo software livre. Gilberto Gil, como artista, já era conhecido por sua "cibermilitância", pela simpatia e proximidade a alguns pressupostos da cibercultura. ${ }^{6}$

Em julho de 2004, o MinC, dentro desse espírito, formulou sua primeira iniciativa voltada para a cultura digital: a proposta de implantação de estúdios digitais de produção audiovisual, conectados à internet e utilizando software livre nos Pontos de Cultura, no âmbito do Programa Cultura Viva. O MinC estabeleceu como diretriz para suas ações três pilares conceituais: autonomia, protagonismo e empoderamento (empowerment), que se relacionariam também a três dimensões da cultura, a simbólica, a cidadã e a econômica. A proposta dos Pontos de Cultura seguia essa filosofia e invertia a lógica de atuação do Estado: em vez de levar ações culturais prontas para as comunidades, são estas que definem as práticas que desejam fortalecer, com reconhecimento e apoio do governo. Esta ação se concretiza no apoio a projetos de espaços culturais, os denominados Pontos de Cultura, selecionados por editais públicos ou em parcerias com estados, municípios e redes dos pontos.

Os Pontos de Cultura envolvem iniciativas relacionadas à arte, cultura, cidadania e/ou economia solidária, conduzidas por organizações não governamentais de caráter cultural e social, legalmente constituídas, já existentes pelo menos dois anos antes de sua seleção, que, mediante editais públicos nacionais, passam a receber recursos do Ministério da Cultura por três anos, para impulsionar ações em suas comunidades, conforme o projeto apresentado, passando a receber recursos diretos do Fundo Nacional de Cultura. Denominada Ação Cultura Digital, a iniciativa procurava potencializar a rede formada pelos Pontos e apresentava um caráter transversal, tanto no âmbito do programa, quanto no do Ministério. Até 2013, o MinC havia investido num total de 3663 pontos e pontões espalhados pelo país (MinC, 2014).

Sem a exigência de um modelo único de atividades, programação ou instalações físicas, os Pontos de Cultura têm em comum, desde seu lançamento, além da gestão compartilhada entre poder público e comunidade, a presença em diversos deles de um estúdio digital multimídia. A primeira parcela do financiamento seria destinada prioritariamente à aquisição do kit multimídia, quando ele não fosse encaminhado pelo próprio MinC. Composto de microcomputadores conectados à internet e utilizando software livre, e de recursos para edição de áudio e imagem, câmera fotográfica, filmadora e equipamento de som, o estúdio viabiliza tanto a produção de conteúdos digitais como vídeos, fotografias, músicas, documentários, blogs, sites e programas para rádios e TVs digitais comunitárias, quanto a difusão dessa produção na rede. A criação dessa teia - a articulação em rede entre os Pontos de Cultura 
A gestão 2003-2010 do MinC caracterizou-se pela busca da incorporação da tecnologia digital às políticas públicas, mas considerando o computador e a internet como pontos de partida, e não como objetivos finais em si, numa concepção de inclusão digital que também era inclusão social - nessa perspectiva, podemos aproximar esse ideário das concepções de Warschauer (2006). Dessa forma, o MinC priorizou não a infraestrutura tecnológica, mas o potencial de transformação suscitado pelos novos paradigmas de produção, circulação e consumo cultural. $\mathrm{O}$ que se buscou foi ampliar as possibilidades de ressonância de expressões culturais (bastante limitada nos meios de comunicação de massa tradicionais), incentivando práticas de compartilhamento, debate, articulação e trabalho colaborativo, apresentando novas perspectivas para o acesso à informação e ao conhecimento.

Segundo dados do IPEA (Instituto de Pesquisa Econômica Aplicada), as principais atividades dos Pontos Digitais são audiovisuais $(71,1 \%)$, vindo na sequência música $(69,8 \%)$, festas populares $(66,8 \%)$ e teatro $(56,2 \%)$. A ordem de frequência das atividades culturais em Pontos que não aderiram ao digital muda, sendo que em primeiro lugar vem a música $(78,8 \%)$, depois as festas populares $(62,9 \%)$, o teatro $(61,9 \%)$ e a dança $(59,6 \%)$. As atividades voltadas à geração de renda também apresentam diferenciações entre os Pontos. Enquanto 32,8\% dos Pontos Digitais desfrutaram de renda proveniente do artesanato, 40,4\% dos não digitais fizeram o mesmo; 17,9\% obtiveram renda de atividades relacionadas à venda de DVD, de vídeo e de outro produto 
${ }^{7}$ Por associação, também compõem o sistema a Biblioteca das Empresas Públicas de Medellín e os centros de documentação.

\section{Marco Antônio de Almeida}

audiovisual; $13,2 \%$, com o concerto musical; $10,2 \%$, com o teatro; e $8,5 \%$, com a dança. A lista muda para os não digitais, cujos maiores percentuais, depois do artesanato, destacam o teatro $(15,9 \%)$ e a dança $(12,6 \%)$ como atividades que geram renda (SILVA, 2011).

$\mathrm{Na}$ avaliação realizada pelo IPEA (SILVA, ARAÚJO, 2010), a ação foi reportada frequentemente como muito importante, mas também foram apontados muitos problemas, entre eles as dificuldades de acompanhamento, assistência técnica inadequada e outras inerentes ao uso de ferramentas livres: a inadequação de algumas delas para uso no campo artístico, em especial no campo audiovisual. Para os pesquisadores, ficou a impressão de que a obrigatoriedade do uso do Linux representou, para muitas instituições, mais um fator de dificuldade do que de facilidade. A falta de intimidade com o sistema operacional somada à falta de suporte efetivo por parte do MinC levou algumas delas a optarem por usar o Windows. Enfatize-se que, em alguns estados, os Pontões ou outros pontos foram indicados como capazes de fazer uso e realizar capacitação adequada nos termos da Cultura Digital. Mas esse processo foi seletivo e insuficiente, já que outros Pontos desses mesmos estados criticaram os processos e a abrangência dessa capacitação. Essa realização "enviesada" dos objetivos da política, mesmo não cumprindo o script proposto (ao utilizar um software proprietário no lugar de um software livre) nos remete à dinâmica estabelecida por Michel de Certeau (1994) entre o emprego de estratégias e o emprego de táticas. Em dois microestudos de caso realizados com dois Pontões, em São Paulo e em Ribeirão Preto
(SP), observamos dinâmicas diferentes. No Pontão paulistano a presença de pessoas que dominam o Linux é maioria, tanto que uma das atividades que gera renda para o Pontão é a oferta de cursos e oficinas de capacitação nessa ferramenta para membros de outros Pontos de Cultura. A seguir detalharemos a atuação de um Pontão de Cultura e de sua conexão com a rede local de Pontos, o que permitirá visualizar melhor o processo.

\section{Sistema de Bibliotecas Públicas de Medellín}

No caso de Medellín, o que desperta a reflexão é, de um lado, a conexão das políticas culturais com outras políticas setoriais, e, de outro, a busca de integração da cultura e dos conhecimentos locais com as formas consagradas de conhecimento cultural. Um dos pilares dessa política cultural, o Sistema de Bibliotecas Públicas de Medellín, compreende a Biblioteca Pública Piloto, os parquesbiblioteca, o Arquivo Histórico e as bibliotecas de bairro ${ }^{7}$. O sistema possui um modelo de gestão cooperativo, coordenado pela Biblioteca Pública Piloto e administrado diretamente pela prefeitura ou por meio de convênios de associação, administração delegada e cooperação. O uso das TICs já se manifesta aqui, na busca de facilitar trocas e proporcionar o diálogo entre os diversos atores e saberes envolvidos, conectando em particular o sistema Municipal à Rede Metropolitana, buscando um desenvolvimento harmônico com os demais programas sociais, em especial os de educação. 
Vale destacar que, em relação ao desenvolvimento urbano, as bibliotecas e os parques biblioteca vêm desempenhando um importante papel na recuperação do tecido urbano e no fortalecimento do capital social. As unidades são geoestrategicamente localizadas, outorgando-lhes um papel detonador de processos de desenvolvimento de territórios com altas densidades populacionais caracterizados por condições de habitação precárias, déficits de equipamentos públicos e zonas de risco socioambiental. São regiões que concentram elevada população em idade escolar e grande número de estabelecimentos educativos, mas sem a contrapartida de equipamentos culturais, desportivos e recreativos, além de barreiras de comunicação, mobilidade e limitado acesso a ferramentas tecnológicas (MEDELLÍN, 2012). A Biblioteca Espanha, uma das maiores, é um exemplo de conexão com outros serviços públicos, especialmente no que diz respeito à acessibilidade: localiza-se próxima a uma estação de teleférico. Em Medellín, a prefeitura instalou essas linhas de teleféricos para estabelecer uma conexão entre os morros, que concentram grande parte da população de menor renda, com o sistema de transporte público de larga escala (metrô/ônibus) que transita no vale, facilitando seu acesso ao trabalho. Sem essa linha de teleféricos, muitos dos habitantes que teoricamente residiriam próximos à biblioteca, não teriam facilidade de acesso à mesma. Em um estudo realizado em 2010 para a Rede Metropolitana de Medellín, constatou-se que $81 \%$ dos usuários eram de estratos socioeconômicos baixo e médio baixo, sendo que o primeiro representava 49\% dos usuários (MEDELLÍN, 2012).

No âmbito instrumental, portanto, os parques biblioteca, com suas associações e conexões, além do impacto sociocultural positivo, vêm colaborando ativamente na redução da "brecha digital" (nos termos de Castells) na cidade de Medellín. Além da agenda cultural e das oficinas de formação e encontro da comunidade, são oferecidos, entre outros serviços: a) serviços de informação, com consulta e empréstimo de material; b) serviços tecnológicos como salas virtuais, bases de dados, oficinas de formação e cadernos digitais (respaldados por 1050 computadores e portal web); c) salas de leitura e estudo com acesso a livros, CDs e DVDs; d) salas "Mi Barrio" (Meu Bairro), cenários para a promoção da história e da memória local.

Do ponto de vista das instalações, chama a atenção o cuidado e o planejamento que é reservado para estes espaços. Os edifícios são fruto de concursos arquitetônicos promovidos pela prefeitura, que escolhe os projetos a partir de sua funcionalidade e adequação ao local - tanto do ponto de vista prático como simbólico. O edifício do parque biblioteca Bélen foi o único cujo projeto não foi resultado de concurso público, sendo uma doação do governo do Japão. A universidade de Tóquio selecionou o arquiteto Hiroshi Naito, que trabalhou com o apoio dessa instituição e, localmente, da Empresa de Desenvolvimento Urbano de Medellín. Ele se mudou um tempo para a Colômbia, vivendo na comunidade, e criou um projeto que visava constituir pontes entre a cultura local 
e a cultura japonesa, além de ter doado sua coleção de livros de arte e arquitetura para a biblioteca. $\mathrm{O}$ resultado foi um conjunto que, além de funcional, possui grande beleza, constituindo-se hoje num dos pontos turísticos da cidade. Muitos desses parques bibliotecas agregam outras atividades e serviços ao espaço - quadras poliesportivas, agências de micro-crédito, postos de realocação de emprego, espaços de requalificação profissional.

Outro aspecto importante no caso dos parques biblioteca é que eles buscam atender a uma estratégia simbólica de redução dos estigmas territoriais e de melhoria da inserção social da população urbana. Muitas dessas unidades foram construídas em territórios nos quais o imaginário da comunidade estava associado a situações ou eventos conflitivos ou dramáticos. O parque biblioteca Léon de Greiff/ La Ladera, por exemplo, ocupou as instalações do antigo Cárcel de Varones (Prisão); o parque biblioteca La Quintana erguese num local que era utilizado como "botadero de cadáveres" (cemitério clandestino das forças de repressão e do narcotráfico); e o Parque Belén ergue-se sobre as antigas instalações da Polícia Judicial e de Inteligência do Estado Maior (instituição similar ao nosso antigo DEOPS). A localização dos parques biblioteca em territórios cujo imaginário da coletividade estava relacionado a fatos ou episódios socialmente conflitivos, como antigos aparatos de repressão (cadeias, quartéis), zonas de conflito com o narcotráfico ou regiões sujeitas a desastres naturais, visava, segundo a administração municipal, reescrever a cidade sobre espaços que outrora foram de dor e morte. Esse cenário ainda não está totalmente distante. Em um dos parques biblioteca, por exemplo, alguns funcionários "negociaram" com representantes de gangues locais que aquele espaço seria uma "zona neutra" - o seja, que os conflitos e disputas não se reproduziriam ali. Foram bem sucedidos, até o momento.

Algumas das formas de mediação cultural da informação confundem-se, dentro da perspectiva de Certeau, com uma nova "produção". Um exemplo são as salas "Meu Bairro", uma iniciativa de conectar o conhecimento local (através de registros de história oral, entre outros), assim como a produção de informações de interesse da comunidade (jornais e impressos locais, ou outras formas de produção dos moradores da região), aos demais serviços das bibliotecas parque. Sintonizam-se, assim, a um objetivo mais amplo, que é o de fortalecimento do tecido social e do aumento da auto-estima dos cidadãos pela modificação dos imaginários coletivos e empoderamento local. Em alguns espaços foram desenvolvidas exposições relacionadas às histórias de ocupação do bairro ou da peculiaridade de algumas atividades locais. No caso do parque biblioteca 12 de Octubre, por exemplo, foi dado destaque ao desenvolvimento de movimentos culturais alternativos na localidade em que a instituição está localizada. Foram recolhidos depoimentos, antigas fotos, objetos que compõem um mapeamento de grupos teatrais, artistas plásticos, eventos, etc. que floresceram apesar das contingências econômicas e políticas. Obviamente, atividades dessa natureza demandam uma equipe com formação interdisciplinar, que é outra das características dessas unidades, que aglutinam não só 
profissionais da informação, como também historiadores, antropólogos, tecnólogos, economistas, arte-educadores.

\section{Considerações Finais: Ambientes de infocomunicação, desenvolvimento social e cidadania cultural}

O contexto de cada uma das experiências culturais descritas anteriormente é bastante específico, mas em sua diversidade é possível alinhavar algumas questões de fundo que são comuns.

No caso dos Pontos de Cultura, sua realidade é muito diversa justamente porque a lógica do Programa Cultura Viva opera com base no apoio a associações socioculturais que já desempenhavam um papel na sociedade mais ampla ou em comunidades locais e específicas. Assim, cada projeto de Ponto de Cultura apresentado pela sociedade civil é estruturado em cima de demandas próprias, necessidades diferentes, que estão diretamente ligadas ao perfil e à capacidade de articulação da organização proponente. Ao atuar com base nessa lógica, a heterogeneidade é algo que necessariamente se faz presente e tem reflexo imediato na análise do programa, tornando muito difícil tecer generalizações simplesmente a partir de seu arcabouço institucional "oficial".

Existe nos Pontos de Cultura uma diferença crucial em sua capacidade de operação e agenciamento que está ligada a um conjunto de fatores, normalmente, vinculados ao desenvolvimento institucional da organização que o abriga e da capacidade de articulação dos atores envolvidos. Da mesma forma, as práticas relacionadas ao digital complementam e agregam maior complexidade às atividades artísticas relacionadas à dança, ao teatro, aos mamulengos, à capoeira, ao maracatu, à congada, ao artesanato e a tantas outras práticas. Além desses aspectos, é bom lembrar que os praticantes estão dispostos a se engajar em práticas culturais com diferentes intensidades e habilidades, mas também encontram nos Pontos as possibilidades de uma oferta muito heterogênea de atividades e de contato com novas formas de conhecimento e informação. Isto, por outro lado, sinaliza também que, para garantir a valorização do sentido emancipatório dessas políticas, é necessário estar atento para o desenvolvimento paralelo das mediações educativas e formativas. Essa convergência de perfis diversos e do papel jogado pelas atividades de formação no empoderamento dos sujeitos pode ser ilustrada pela experiência de Medellín. Outro aspecto importante presente nesse exemplo foi a equalização de perfis inter e multidisciplinares na efetivação dessas ações, perceptível no quadro funcional das bibliotecas parque, composto não só por bibliotecários, mas também por antropólogos, historiadores, pedagogos, informáticos, arte-educadores, etc.

As questões levantadas pelas experiências concretas dos Pontos de Cultura ilustram algumas das potencialidades desse modelo de política cultural proposto pelo MinC, bem como algumas de suas dificuldades e desafios. De um lado, superar as dificuldades técnicas inerentes às TICs e à sua implementação e apropriação, bem como os trâmites burocráticos e dificuldades no acesso a recursos financeiros; de outro lado, lidar com a heterogeneidade dos grupos, a partir da articulação das entidades culturais no "micro" ou 
"médio" espaços públicos constituídos pela rede formada por um Pontão envolve um processo de aprendizagem do diálogo e da administração de controvérsias que implica conflitos, constituição de acordos, avanços e recuos que caracterizam um processo que se desenvolve num período de tempo que nem sempre atende às expectativas ou à própria dinâmica dos atores envolvidos.

As práticas e políticas culturais de mediação brevemente discutidas apontam para essa complexidade, ilustrando como a construção de processos de mediação cultural voltados para o empoderamento dos atores enfrenta dificuldades de distintas naturezas para tentar se enraizar socialmente. A existência da cultura popular demanda uma sensibilidade diferente: seus modos de produção do sentido e de articulação no simbólico a partir de uma pluralidade de experiências estéticas e dos modos de fazer e usar socialmente a cultura e a arte são contradições presentes nesse cotidiano. Políticas culturais fundadas numa perspectiva esquemática e instrumental de "acesso", "transmissão" ou "disseminação" de conhecimentos e valores institucionalmente legitimados não são a melhor opção para se pensar essas situações.

A questão das mediações sociais nos contextos formativos das políticas e ações culturais mereceria uma maior reflexão. Tratase do desafio de incorporar uma cultura pedagógica apoiada em formas de experiência que não se restringem à mediação escrita, ligadas a modos de negociação entre conteúdos e significados historicamente muitas vezes estigmatizados, discriminados e deslegitimados. A construção do conhecimento é aqui um fenômeno ao mesmo tempo individual e social, e o saber, um "produto" da construção ativa dos sujeitos, mediada técnica, artística e culturalmente. Os exemplos das salas "Meu Bairro" nas bibliotecas parque de Medellín nos permitem verificar que iniciativas dessa natureza são possíveis.

Os aspectos educativos da mediação - a capacitação dos sujeitos envolvidos no uso das tecnologias - mostraram-se, em larga medida, o calcanhar de Aquiles das iniciativas brasileiras. Na já mencionada avaliação realizada pelo IPEA (SILVA; ARAÚJO, 2010), esta dificuldade aparece como um desafio a ser superado. No período da gestão da ministra Ana de Hollanda (2011/2012), além dos cortes nos repasses financeiros, o que se pôde observar foi uma descontinuidade em relação às políticas anteriores de integração e inclusão cultural por meio da internet e tecnologias digitais, compreendendo a discussão de direitos autorais, livre circulação de material cultural pelas redes e formação e capacitação de agentes culturais via Telecentros e Pontões Culturais. Mesmo com a substituição da ministra em questão pela senadora Marta Suplicy, a retomada do programa, especialmente no que tange aos repasses de verba que viabilizam essas iniciativas, não foi plenamente cumprida. Atualmente, o retorno de Juca Ferreira à pasta acena com um cenário mais positivo em relação à abertura aos movimentos culturais e à resolução destes problemas, muito embora a crise econômica e a contenção de verbas promovidas em todos os âmbitos de governo obscureça o horizonte. 
A efetividade dessas ações, todavia, depende de muito mais do que do simples voluntarismo ou do potencial democrático das políticas. A atuação em rede, e não a estritamente tecnológica, mas especialmente a semântica e humana, é ao mesmo tempo uma possibilidade e um desafio. Manifestações culturais específicas, como o teatro popular ou as expressões musicais - cuja visibilidade costuma recair muitas vezes sobre artistas individuais ou pequenos grupos, contando com um expressivo número nas cidades -, parecem apresentar maior facilidade neste tipo de atuação em subunidades institucionais com diferentes níveis de mediações. Atividades do gênero são vistas em muitos projetos dos Pontos de Cultura, assim como nos projetos das bibliotecas-parque de Medellín.

Unidades de Informação, Espaços Culturais, Unidades Híbridas... a terminologia cambiante poderia denunciar a falta de rigor metodológico - mas preferimos pensar que reflita, antes, a riqueza e multiplicidade das instituições e situações possíveis nesse cenário dinâmico que aproxima as TICs à cultura. Assim, procuramos destacar o valor social e o significado cultural desses lócus. Longe de opor tradição à inovação, parece-nos antes que esta última só se realiza quando consegue lidar criativamente com a primeira. Isso vale tanto para a incorporação das tecnologias, como para a configuração de novos serviços e funcionalidades para os cidadãos e as comunidades que se relacionam com estas instituições. Desenham-se assim as possibilidades de constituição de novas ações e cadeias de mediações, numa perspectiva muito mais dialógica que impositiva.

Diante dos atuais conflitos públicos nos modos de representar a vida social, Yúdice (2006, p. 47) chamará atenção para a função política dos “mediadores” na elaboração e implementação de "políticas socioculturais" que criem espaços onde as distintas narrativas culturais possam ser "concebidas e tornadas compatíveis". O encontro de indivíduos e de grupos com as instituições merece ser compreendido como um processo complexo povoado por práticas heterogêneas e não excludentes. Nesse sentido, vale relembrar a lição de Michel de Certeau (1994), ao apontar não as restrições impostas pelos aparatos aos indivíduos, mas a criatividade das práticas sociais, para voltarmos nosso olhar para a apropriação das tecnologias e das informações nos processos vivos de produção e circulação da cultura.

\section{Referências}

ALMEIDA, Marco A. Mediações da cultura e da informação: perspectivas sociais, políticas e epistemológicas. Tendências da Pesquisa Brasileira em Ciência da Informação v. 1, n⿳0 $1,2008$.

Habermas e as apropriações culturais das TICs: rumo a ciberesferas públicas? Problemata: R. Intern. Fil. Vol. 03. Nº 02 , pp. 127-156, 2012.

. Políticas culturais e redes sociotécnicas: reconfigurando o espaço público. Revista Ciências Sociais Unisinos, São Leopoldo, Vol. 50, N. 1, p. 54-64, jan/abr 2014

AUGÉ, Marc. Não-lugares. Introdução a uma antropologia da supermodernidade. 3a. ed. Campinas: Papirus, 1994. 
BENJAMIN, Walter. O Narrador. Considerações sobre a obra de Nikolai Leskov. In: Obras Escolhidas vol. 1. São Paulo: Brasiliense, 1987b, p. 197-221.

BERGER, Peter \& LUCKMANN, Thomas. A construção social da realidade. Petrópolis $(\mathrm{RJ})$ : Vozes, 1974

CASTELLS, Manuel. Internet e sociedade em rede. In: MORAES Denis de (org.) Por uma outra comunicação: mídia,

mundialização cultural e poder. Rio de Janeiro: Record, 2003b, p. 255-288.

CERTEAU, Michel de. A invenção do cotidiano: 1. artes de fazer. Petrópolis (RJ): Vozes, 1994.

CUNHA, Newton. Cultura e Ação Cultural. São Paulo: Edições SESC, 2010.

DAVALLON, Jean. A mediação: a comunicação em processo? Revista Prisma.Com, n. 4, 2007, p. 03-36.

GLEICK, James. A informação: uma história, uma teoria, uma enxurrada. São Paulo: Companhia das Letras, 2013

HABERMAS, Jürgen. Consciência moral e agir comunicativo. Rio de Janeiro: Tempo Brasileiro, 1989.

HALL, Stuart. A centralidade da cultura: notas sobre as revoluções culturais do nosso tempo. Educação \& Realidade, Porto Alegre, v 22, nº2, p. 15-46, jul./dez.1997.

ISAR, Yudhishthir Raj. Políticas de cultura: questões para uma análise comparativa transnacional. In: LEITE, José Guilherme Pereira (org.) As malhas da cultura 2. Cotia (SP): Ateliê Editorial, 2013, p. 13-36.

LOGAN, Robert K. Que é informação? A propagação da organização na bisofera, $n$ simbolosfera, na tecnosfera e na ecosfera. Rio de Janeiro: Contraponto, 2012.

LUHMANN, Niklas. Poder. Brasília: Editora da UNB, 1985.

MEDELLÍN, Alcadia. Laboratorio Medellín: catálogo de diez prácticas vivas. Medellín: Alcadía de Medellín/Mesa Editores, 2012
MinC Ministério da Cultura. Pontos de Cultura. Disponível em http://www.cultura.gov.br/pontos-de-cultura1 . Acesso em 23/09/2014.

PIGNATARI, Décio. Informação Linguagem Comunicação. Cotia (SP): Ateliê Editorial, 2002.

SANTOS, Gildenir Carolino; RIBEIRO, Célia M. Acronicos, siglas e termos técnicos. Campinas: Átomo, 2003.

SHIRKY, C. Ontologias são superestimadas: categorias, links e etiquetas. Extralibris. Disponível em: http://extralibris.org/artigose-estudos/ontologias-sao-superestimadas-categorias-links-eetiquetas Acesso em: 10 abr. 2015

SILVA, Frederico Barbosa A. Cultura viva e o digital. In: SILVA, F. B. A.; CALABRE, L. (orgs.) Pontos de Cultura: olhares sobre o programa Cultura Viva. Brasília: IPEA, 2011, p. 13-59.

SILVA, F. A. B.; ARAÚJO, H. E. Cultura Viva: avaliação do Programa Arte Educação e Cidadania. Brasília: IPEA, 2010.

THOMPSON, John. A mídia e a Modernidade: uma teoria social da mídia. Petrópolis (RJ): Vozes, 1998

TOLILA, Paul. Cultura e economia. São Paulo: Itaú Cultural: Iluminuras, 2007.

VIANNA, Hermano. Internet e inclusão digital: apropriando e traduzindo tecnologias. In: Schwarcz, L. M.; Botelho. A. (orgs.) Agenda brasileira: temas de uma sociedade em mudança. São Paulo: Companhia das Letras, 2011, p. 314-323.

WARSCHAUER, Mark. Tecnologia e inclusão social: a exclusão digital em debate. São Paulo: Senac, 2006

WAL, Thomas Vander. Folksonomy Coinage and Definition. Fevereiro/2007. Disponível em

http://www.vanderwal.net/folksonomy.htm

YÚDICE, George. A conveniência da cultura: usos da cultura na era global. Belo Horizonte: UFMG, 2006. 